\title{
An Empirical Study on the Cultivation Path of Craftsman Spirit for Higher Vocational College Students
}

\author{
Zhaojie Cao, Lishan Ding \\ School of Education and Psychological Science, Sichuan University of Sciences \& Engineering, Zigong, China
}

Email address:

zjcao@suse.edu.cn (Zhaojie Cao)

To cite this article:

Zhaojie Cao, Lishan Ding. An Empirical Study on the Cultivation Path of Craftsman Spirit for Higher Vocational College Students. Higher Education Research. Vol. 6, No. 2, 2021, pp. 51-57. doi: 10.11648/j.her.20210602.14

Received: March 25, 2021; Accepted: April 10, 2021; Published: April 26, 2021

\begin{abstract}
With the advent of the Industry 4.0 era, China's manufacturing industry is facing the challenges of upgrading from "Made in China" to "Quality in China". Where there is a high quality product there is a high-skilled talent. Higher vocational colleges as the cradle of talent cultivation, should not only serve as a source of high-lever technology talents to support the country's high-quality development, but also provide talents with craftsman spirit to encourage them to make high quality products. How to cultivate "craftsman spirit" is an important issue for higher vocational education in China. This article focuses on the study of the training path of "craftsman spirit" in higher vocational college so as to provide suggestions and strategies for training of the artisan spirit of higher vocational college students. Firstly, it elaborates the connotation and its main elements of the craftsman spirit for a better understanding of the concept. Then it analyzes some issues in cultivation of the craftsman spirit in higher vocational college and makes an empirical analysis on the key factors which influence the training effects of higher vocational college students' craftsman spirit from the perspective of the enterprises, schools, governments, families and individuals. Thirdly, it discusses how to train the craftsman spirit of higher vocational college students as well as the responsibilities of each party who is involved such as teachers, parents, schools and society in the cultivation of craftsman spirit respectively. Finally, it explores the ways of the cultivation of the spirit of craftsman and vocational skills from the aspects of campus culture, school-enterprise cooperation, and teacher team construction and combines the procedure for training the craftsman spirit for vocational students.
\end{abstract}

Keywords: Vocational Education, Craftsman Spirit, Vocational Skills

\section{Introduction}

Under the background of economic transformation, high-skilled talents, especially high-quality skilled talents with craftsmanship spirit, are in the badly needs in the processing of high-quality development in the new era. Craftsman spirit grows in the enterprises, but it sprouts in education, especially in vocational education. The focuses of this study are as follows. What is the important step in the cultivation of craftsman spirit? What are the responsibilities of teachers, parents, schools and society in the cultivation of craftsman spirit? What is the specific cultivation path of craftsman spirit? This study explores the cultivation of craftsman spirit in higher vocational college students through empirical research, in order to provide references to the promotion of craftsman spirit in higher vocational college students.

\section{Literature Review and Research Hypothesis}

The discussion of craftsman spirit originated from the priority to feelings and specialized skills. Some scholars believe that feelings come first. When evaluating first-class talents, Akiyama Lihui (2015) believes that character, feelings and aesthetics take up more weight, followed by professional skills [1]. The former Dean of Harvard College Harry Lewis (2012) has a similar view. He believes that if a student only masters a certain specialized skill and can only take it as a means of earning a living, then his life lacks interests [2]. Apart from being related to personal factors, educational interest has an important influence. When analyzing the purpose of education, Lu Baoli et al. (2016) 
directly comes to the point of the weakness in vocational education, believing that vocational education highlights the "ability standard" excessively which made the negligent craftsman spirit further affected. It is one of the reasons for the dating of Chinese craftsman spirit [3]. There are also scholars who specialize in the spirit of craftsmen. Through combing, it is found that the scholars think the spirit of craftmen contains feelings and specialized skills.

\subsection{Composition of the Craftsman Spirit}

\subsubsection{Craftsman Spirit Includes Professional Skills from the Aspect of Technical Dimension}

$\mathrm{Hu}$ Bing and Li Xiaolu (2015) decomposed the craftsman and spirit. They believe that the craftsman emphasizes the skills and techniques from the professional aspect of production [4]. Li Defu and Liao Yi (2016) also believe that the craftsman spirit embodies the specialized skills and unique skills [5]. Cheng Hong and Tian Hongmiao (2016) divide the craftsman spirit as a variable and analyze that the craftsman spirit includes two connotations: professional spirit and professional ability, both of which have a positive correlation with the quality of enterprise products [6]. Manova (2012) also pays attention to the relationship between product quality and craftsman spirit. He divides the connotation of product quality and proposes that different quality connotations have different requirements on skills [7]. Hasenkamp (2013) explores the correlation between enterprise performance and employees' innovation ability and found that the stronger the employees' innovation ability, the higher the enterprise performance [8]. From the perspective of scholars' research, it is found that the research context is clear. From the professional and technical level, the craftsman spirit focuses on solid professional skills and improving the level of skills. Only with a solid technical foundation can there be quality improvement and good enterprise performance.

\subsubsection{Craftsman Spirit Includes Personality Quality and Professional Pursuit from the Aspect of Spiritual Dimension}

From the spiritual perspective, scholars take the personal quality as craftsman spirit's first position. Foege (2013) emphasizes the innovative spirit and points out that the craftsman spirit does not only exist in craftsmen, but also in people who use modern craft and technical tools and have the innovative spirit to solve various practical problems [9]. Xiao Qunzhong and Liu Yongchun (2015) emphasize the spirit of excellence, believing that the craftsman spirit is condensed on all people that pursue the attitude and quality of excellence [10]. Tang Yan and Ji Aiqin (2017) point out clearly that excellence is the soul of craftsman spirit [11].

Some scholars have raised it to a deeper spiritual level. Fauci (2014) defines the craftsman spirit as a professional pursuit. He believes that those who have dreams, dare to work hard for them and solve problems creatively are called craftsmen. However, the craftsman spirit is not only the professional spirit of craftsmen, but also of various professions [12]. Li Jin (2016) analyzes the craftsman spirit and comes to a similar view. He believes that love and dedication are its foundation, and the craftsman spirit is professional thinking, attitude and ethics under the influence of a certain outlook on life [13].

From the research of the above scholars, the craftsman spirit is not the exclusive term of craftsmen, but the state of everyone's study, work and life, including the professional ethics of love and dedication, the working attitude towards excellence, and the professional pursuit of truth- seeking and innovation.

\subsubsection{Craftsman Spirit Includes the Value Orientation from the Unity of Knowledge, Action and of Perfection from the Perspective of Value Dimension}

In addition to the technical and spiritual dimensions, scholars have discussed the craftsman spirit from the value dimension. After comparing the craftsman spirit of China, Germany and Japan, Li Defu and Liao Yi (2016) believe that China draws too much horizontally and inherits too little vertically. The craftsman spirit should become the professional norm of Chinese. From the perspective of value, it should be recognized rationally with the unity of knowledge and action [5]. Xiao Qunzhong and Liu Yongchun (2015) find that craftsman spirit is a pursuit of perfect value orientation and lofty beliefs by analyzing craftsmanship, ingenuity and spirit [10].

\subsection{The Cultivation of Craftsman Spirit Is a Kind of Formative Education}

Whether the educated produce ideal results in ability, virtue and psychological accomplishment or is influenced by the seen and heard practical behaviors and habits, it is necessary to internalize knowledge, norms and morality into personal accomplishment. The process of internalization is the cooperation among enterprises, schools, society, families and individuals.

The production-education integration and school-enterprise cooperation are important carriers for the cultivation of craftsman spirit (Li Jin, 2016) [13]. Yang Hongquan and Su Wei (2016) find that the cultivation of craftsman spirit must be based on the modern apprenticeship system. Enterprises are the main body of collaborative cultivation. They take great effect as the guiding role and formulate corresponding assessment standards and apprenticeship norm system [14]; Coincidentally, Ma Yinqiu and Ma Canjing (2017) find that the establishment of traditional "stable mentoring system" enterprise institutional culture is one of the ways to reshape the spirit of craftsmen [15]. Polach (2004) puts forward the "sandwich" model of "study + work + study" when studying vocational education in Britain. He believes that the model combined teaching in school with enterprise practice organically. It not only increased students' employment opportunities, made them positive and confident, but also mastered work skills [16]. Based on this, the first research 
hypothesis of this study is proposed:

H1: Enterprises' emphasis and training of craftsman spirit have a positive impact on the cultivation of craftsman spirit.

The educational function of higher vocational colleges provides basic guarantee for the cultivation of craftsman spirit (Li Jin, 2016) [13]. The cultivation of craftsman spirit requires higher vocational colleges to carry out quality education activities to influence students imperceptibly through daily teaching activities in schools (Yang Hongquan and Su Wei, 2016; Cheng Haitao, 2016) [14, 17]; In terms of specific development, Hu Bing and Li Xiaolu (2015) believe that it is necessary to focus on the rationality of cultivating technology and value in higher vocational education, so as to serve the cultivation of professionalism, professional attitude and humanistic quality [4]; Liu Qing (2017) proposed that the cultivation of craftsman spirit in higher vocational colleges should be carried out from the knowledge level, belief level and behavior level hierarchically as follows: optimize the talent training scheme, strengthen the construction of teaching staff to guide the formation of craftsman spirit core values, and build the multi-level practice platform and good campus culture. The above are all based on the theory of knowledge, belief and practice model [18]. Lu Baoli et al. (2016) also stresses that vocational education should carry out curriculum reform, and the "craftsman spirit" factor needs to be treated as "curriculum" [3]. Based on this, the second research hypothesis of this study is proposed:

H2: The schools' emphasis and cultivation of craftsman spirit have a positive impact on the cultivation of craftsman spirit.

In addition to school education and enterprise practice, scholars also paid attention to the creation of the external environment for the craftsman spirit. Yang Hongquan and $\mathrm{Su}$ Wei (2016) point out that the cultivation of craftsman spirit requires the government to guide the transformation of social concepts on study and employment, formulate an effective prompting system, and improve the social status of craftsmen [14]. Kuang Ying (2018) stresses the need to build a good social support system and create an atmosphere of public opinion that respects the spirit of craftsmen through positive publicity and guidance [19]. On the other hand, Tan $\mathrm{Lu}$ (2018) believes that government should attach importance to the protection of intellectual property so that craftsmen's craftsmanship, technology and patent elements can flow in the market freely to reflect the market value fully [20]. Based on the above, the third research hypothesis of this study is put forward:

H3: H3a: The more the government pays attention to guiding the craftsman spirit, the more beneficial it is to the cultivation of the craftsman spirit.

$\mathrm{H} 3 \mathrm{~b}$ : The more the family recognizes the craftsman spirit, the more conducive it is to the cultivation of the craftsman spirit.

$\mathrm{H} 3 \mathrm{c}$ : The stronger the sense of professional, the better it is for the cultivation of craftsman spirit.

\section{Scale Design and Questionnaire Distribution}

At present, domestic research scales for the influence of craftsman spirit are mostly designed from three aspects: enterprises, schools, and governments. Drawing on the achievements of scholars, it added the influences of family and individual at the same time. The mental state scale designed a research scale based on the results of combing the dimensions of craftsman spirit. In order to ensure a better content validity of the scale, a small-scale pre-investigation was carried out on the initial scale, and the reliability and validity of the scale were tested. The items in the scale with a correlation coefficient less than 0.4 between the items and the overall were deleted to form the final scale. The questionnaire consists of three parts: the first part with a total of five questions is the state of craftsmen spirit, the second with a total of 19 questions is the influencing factors of craftsman spirit, which is designed from five aspects: school, enterprise, government, family and individual, the third part with a total of 5 questions is personal basic information. The items in the first two parts were measured by Linkert5 scale.

In the process of combing literature, it was discovered that the cultivation of craftsman spirit was influenced by many factors such as schools, enterprises, social environment and individuals. This study abandons the current practice that many studies focus on students in schools. Because these students lack enterprise practice experience, it is difficult to understand the influencing factors of enterprise. Therefore, this study restricts the research objects to graduates who have carried out graduation practice and are about to graduate and those who have graduated with three years' working experience. The issuance of formal questionnaires, mainly using the paper questionnaire distributed to studengs who is studing in higher vocational colleges and alumni graduation. It covers 15 higher vocational colleges in 9 provinces and municipalities directly under the Central Government of Zhejiang, Henan, Shanxi, Anhui, Hubei, Shandong, Tianjin and Beijing. The subjects studied by the respondents involved literature, art, education, law, economy, management, science, industry, agriculture, medicine, etc. A total of 350 questionnaires were distributed. Due to the on-site filling of the questionnaires, the questionnaire's recovery rate was $100 \%$, and 309 valid questionnaires were obtained after the questionnaire selection, with a valid questionnaire recovery rate of $88.29 \%$.

\section{Empirical Analysis}

\subsection{Variable Setting and Research Methods}

The study involves five variables: the refinement of craftsman spirit, the cultivation of schools, the training of enterprises, the recognition of society and the professional kinetic energy of individuals. Each variable is measured by 
specific indicators. The specific description of the variables is shown in Table 1:

Table 1. Qualitative Description of Variables.

\begin{tabular}{lll}
\hline Variable Name & Metrics & Units \\
\hline $\begin{array}{l}\text { the refinement of craftsman } \\
\text { spirit }\end{array}$ & $\begin{array}{l}\text { eexcellent skills and working attitude, enterprising working habits, professional pursuit of } \\
\text { dedication and innovation, and craftsman spirit become the value orientation } \\
\text { teachers' teaching ability, teachers' professionalism, professional setting, } \\
\text { curriculum Setting, talent cultivation concept, school culture } \\
\text { the cultivation of schools } \\
\text { attach importance to training, systematic assessment system, high incentive, high salary, and } \\
\text { respect the corporate culture of craftsman spirit } \\
\text { positive public opinion guidance, high social status, high social value, parents' } \\
\text { encouragement and recognition, and parents' role model }\end{array}$ & Five-level scale score \\
$\begin{array}{l}\text { the recognition of society } \\
\text { the professional kinetic energy } \\
\text { of individuals }\end{array}$ & professional recognition, professional honor, professional kinetic energy and dedication scale score & Five-level scale score \\
\hline
\end{tabular}

Source: Organized by the author

Linear regression method is often used to explore the relationship between variables, however, the relationship between the variables is often complicated, and one variable is not only the cause variable of a certain variable, but also the result variable of another variables. Path analysis can test the causal relationship between multiple variables, which can not only show the influence path between variables, but also reflect the direct and indirect influence relationship. Therefore, this study uses statistical software AMOS25 to analyze the path of the above variables.

\subsection{Data Stationary Test}

In order to ensure the validity of the estimation results, before conducting empirical analysis, we should first test the stationarity of each panel series to avoid the pseudo-regression problem caused by the instability of panel data. The unit root test of panel data is carried out by using Eviews11, and the test results show that it is statistically significant at the significance level of $5 \%$, indicating that the variables are stable.

\subsection{Action Result Path and Analysis}

AMOS is used to perform model estimation on the calculated estimated value. The model square box displays information such as: chi-square value and degree of freedom of the model, which indicates that the model can be identified, and the significance probability value $\mathrm{P}$ does not reach the significance level of 0.05 . Therefore, null hypothesis is accepted, and the observation data can be adapted to the hypothetical model. At the same time, the values of IFI, TLI and CFI are all greater than the ideal value of 0.9 , which indicates that the overall model has good adaptability.

After the preset model is verified, the output path diagram is shown in Figure 1. The figure shows the parameters of the standardized estimation value. There is no negative value in the variance value in the figure, which indicates that the parameters estimated by the model are reasonable and excludes the existence of unreasonable parameters in the model estimation. Combined with the parameters and test values of path analysis, the absolute values of $\mathrm{C} R$ critical value in the output data of the model are all greater than 1.96, indicating that all five paths reach a significant level of 0.05 ;
From the perspective of $\mathrm{P}$ value, they are all less than 0.05 , which is significant at the level of $1 \%$, indicating that the regression coefficients of the effects of the five straight lines in the figure all reach a significant level. At the same time, there is no correction index value in the output result of the preset model, so it is assumed that the model can fit with the sample data, and there is no need to consider adding or deleting path coefficients.

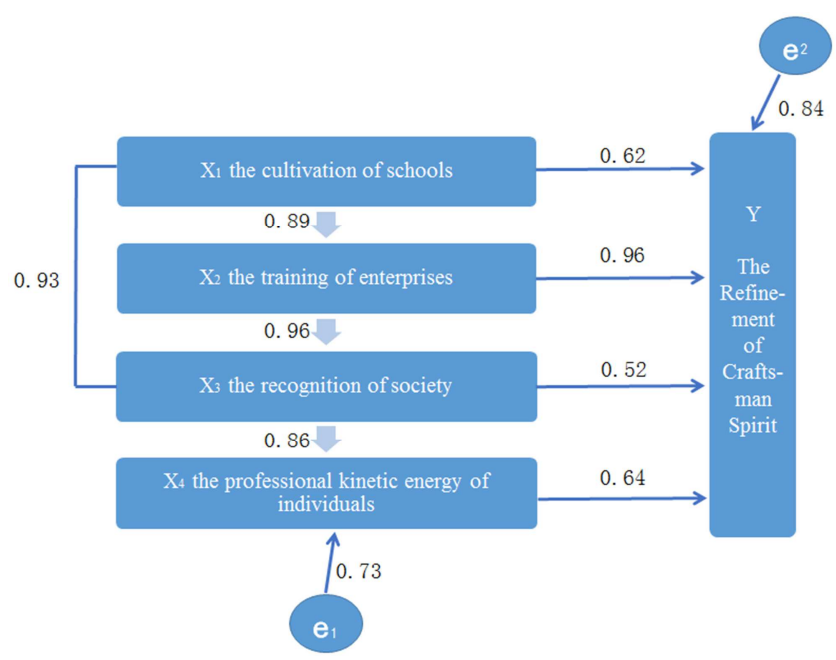

Figure 1. Path diagram of effective influence of various factors on craftsman spirit refinement.

From the perspective of influence direction, there are four external variables in the model design. They are the cultivation of schools, the training of enterprises, the recognition of society and the professional kinetic energy of individuals. The endogenous variables include personal professional kinetic energy and the refinement of craftsman spirit. The four cause variables have a direct and positive effect on the refinement of craftsman spirit. The direct effect of school cultivation on the refinement of craftsman spirit is 0.62 , that is, the degree of attention paid by school to craftsman spirit affects the refinement of students' craftsman spirit positively. The direct impact of enterprises' training on the refinement of craftsman spirit is 0.96 , that is, after students graduate and join the enterprise, the more the enterprise pays attention to the cultivation of craftsman spirit, the more positively it will affect the refinement of craftsman 
spirit. The direct impact of social recognition on the refinement of craftsman spirit is 0.52 , that is, the more society and families attach importance to craftsman spirit, the more positively it will affect the refinement of craftsman spirit. The direct effect of individual's professional kinetic energy on the refinement of craftsman spirit is 0.64 , that is, the stronger the person's professional sense, the more positively it will affect the refinement of craftsman spirit. In addition, social recognition has a positive and direct impact on individual's professional kinetic energy, with an impact value of 0.86 , which affects the refinement of craftsman spirit indirectly through individual's professional kinetic energy.

From the perspective of influence degree, by comparing the total influence effect value, it is discovered that the training of enterprises has the greatest total influence effect value on the refinement of craftsman spirit, which indicates that the training of enterprises paying attention to craftsman spirit has the greatest influence on the refinement of craftsman spirit. The refinement of craftsman spirit by social recognition ranks the second in the total impact ranking, with a direct impact value of 0.52 , which is the lowest compared with the other three factors. However, after indirect impact is generated by influencing individual's professional kinetic energy, the total impact ranking is ahead of individual's professional kinetic energy and school cultivation, with a total impact value of 0.67 . The total impact value of individual's professional kinetic energy on craftsman spirit is closely followed, ranking the third in the total impact ranking, with an impact value of 0.64 . The influence of school cultivation on craftsman spirit with 0.62 ranks the fourth. On the whole, except that the training influence value of enterprises is far ahead, the influence value of the other three elements is not obvious, which basically fluctuates around 0.65 , indicating that the influence of the three elements on the refinement of craftsman spirit is equal. As shown in Table 2:

Table 2. Effects of Model Variables.

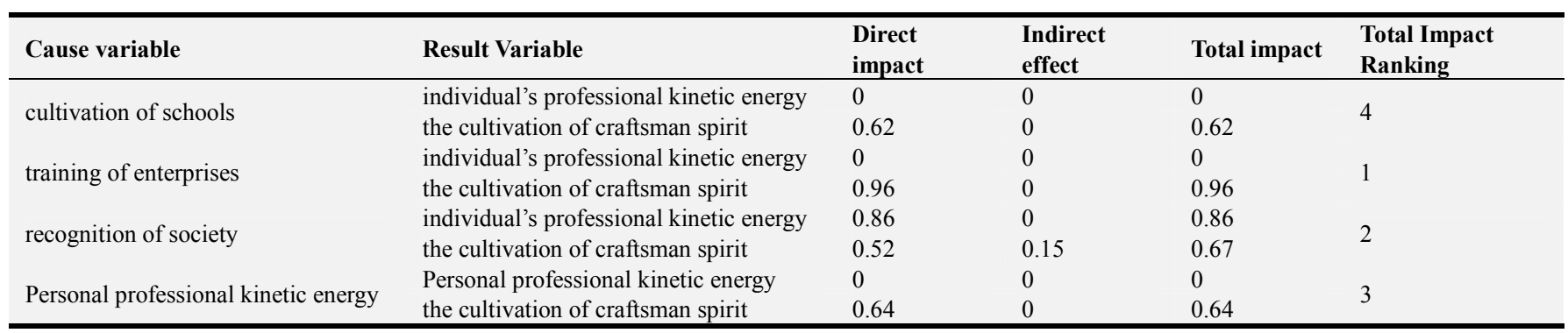

Source: Organized by the author

\section{Research Conclusions and Suggestions}

The results of path analysis show that factors such as school cultivation, enterprise training, social recognition and individual professional kinetic energy all have an impact on the refinement of craftsman spirit. According to the magnitude of the impact, they are enterprise training, social recognition, individual's professional kinetic energy and school cultivation.

\subsection{Increase the Enterprises Practice Such as Work-Study Combination and Learn the Craftsman Spirit by Immersion}

Enterprises attach importance to craftsman spirit and strengthen the training of craftsman spirit in their work, which has a direct positive impact on the refinement of craftsman spirit, and supports Hypothesis 1. The standardized path coefficient of training in $\mathrm{X} 2$ enterprises to the refinement of $Y$ craftsman spirit is 0.96 , which indicates that enterprises attach importance to craftsman spirit and strengthen the training of craftsman spirit in their work has a significant positive correlation with the refinement of craftsman spirit.

Therefore, for students in higher vocational colleges, it is necessary to increase and arrange students' enterprise practice in the form of work-study combination, on-the-site internships every semester. There are not only strict requirements for the duration of enterprise practice, but also clear practical requirements. Students are required to work with the requirements of formal employees, so that students can realize the craftsman spirit in their work. For higher vocational students who have no work experience, the immersion influence of enterprises is the most direct and obvious. As long as the enterprise attaches importance to the spirit of craftsman ideologically, strengthens training in the work, provides learning opportunities for employees to continuously improve their technical level, respects the corporate culture of craftsman spirit, and gives positive incentives to employees with excellent technology, it will promote the emergence of employees with craftsman spirit. With the craftsman spirit planted in the soil and internalized into the spiritual quality of all employees, products, quality, production, research, etc. are naturally improved. The processes of combining with high quality products, the most valuable brands, and 100-year-old enterprises are natural. Students can acquire craftsman spirit unconsciously in this kind of enterprise culture.

The most urgent task at the moment is to cultivate and select a group of enterprises with craftsman spirit and corporate culture. These enterprises should strengthen the training mechanism to allow the workers to stand out and become stars of the enterprise, the incentive mechanism for technical talents to get the rewards they deserve. At the same 
time, the system construction of craftsman spirit should be carried out, so that craftsman spirit can not only guide the employees spiritually, but also how to do it. On the other hand, the realization of school-enterprise normal operation makes students are employees and employees are students. It not only provides students with more opportunities for enterprise practice, but also energies for enterprises' talents team building and innovation according to the win-win cooperation between schools and enterprises.

\subsection{School-Enterprise Linkage, Integration of Teaching, Solidification of Craftsman Spirit}

Schools attach importance to craftsman spirit and inject it into teaching and research, which has a direct positive impact on the refinement of craftsman spirit and supports research hypothesis 2. The standardized path coefficient of the cultivation of $\mathrm{X} 1$ school to the refinement of $\mathrm{Y}$ craftsman spirit is 0.62 , which indicates that the school attaches importance to the craftsman spirit and strengthens the cultivation in teaching and has a significant positive correlation with the refinement of craftsman spirit.

Students in higher vocational colleges experience and learn the craftsman spirit in process of their study and practice. In the teaching, we should focus on the students' professional skills and infiltrate craftsman spirit constantly. Teachers should strengthen the double-qualified construction on them. On the one hand, the school invites experienced professional and technical personnel from enterprises to guide professional construction and students' practice. On the other hand, professional teachers are sent to enterprises for temporary training. Through the introduction and delivery activities, schools can master the requirements of talents in the industry and the directions of skill cultivation. At the same time, teachers' professional practice ability can be improved. School-enterprise linkage can open up the bridge between theory and practice. On the basis of experiential learning in enterprises and professional education in schools, students can get what it is and why.

The craftsman spirit should be integrated into all aspects of education and teaching organically. It needs to be infiltrated systematically and continuously for a long time. The construction of professional courses and teachers' team should not only do a good job of design demonstration, but also do regular effect inspection work, paying attention to the rationality of the connection between basic and professional ability curriculum design, and the matching between teachers' team and students' cultivation. In daily teaching, the teaching content, scheme, practice and homework are integrated into the cases and evaluations of craftsman spirit. Through accumulated training, the unity of ideological and action consciousness is realized, while knowledge and action is achieved. At the same time, it is also important to build campus culture which highlights the cultural mission of universities. Campus culture contains the essence of craftsman spirit which cultivates students' ability and accomplishment imperceptibly and guides the college students get their mission. Before students enter the work position, craftsman spirit is reflected in professional ethics, ability, attitude and ideal deeply, thus forming a perfect value orientation.

\subsection{Carry Forward the Social Atmosphere That the Whole People Respect Craftsmen, Internalize and Drive the Inheritance of Craftsman Spirit}

There is a positive influence between the society's emphasisis on the craftsman spirit and its refinement. It is supported by research hypothesis 3 . Among them, the direct influence coefficient of $\mathrm{X} 3$ social recognition on the refinement of $Y$ craftsman spirit is 0.52 , and the indirect influence on the refinement of craftsman spirit through personal professional kinetic energy shows that social recognition has a significant positive correlation with the refinement of craftsman spirit.

To maintain the durability of the extension driving force, the internal driving force needs to be exerted. Therefore, it is necessary for the government to guide the publics' opinion, carry forward a positive social environment, attach importance to the role of craftsmen in economic development, improve the social status of craftsmen continuously, provide reasonable policy supports and institutional guarantees, create an atmosphere in which the whole society respects craftsmen, and recognize, carry forward and inherit the craftsman spirit. Under the promotion of the social environment, it is also conducive to the education of domestic craftsman spirit. The earliest individual education is family education, which plays a fundamental role in individual education. Parents who are affirmed positively in society and enterprises because of their excellence at work will also teach their children this professional spirit, ethics and ideals by words and deeds. The craftsman spirit is transmitted from the education of social to family then to the personal itself.

Personal education is the key to internalization drive. The direct influence coefficient of X4 individual's professional kinetic energy on $\mathrm{Y}$ craftsman spirit is 0.64 . It shows that there is a significant positive correlation between the professional recognition, honor and dedication in personal work and the refinement of craftsman spirit. Compared with the external thrust to the refinement of craftsman spirit: schools, enterprises, society and families, individual's professional kinetic energy is a powerful internal thrust. It is necessary to create a fair and equitable working environment and do a good job in both spiritual and material. First of all, students should accept this profession from the heart and discipline themselves in daily study and basic skills. The recognition from profession to individual, society and family makes the individuals full of professional pride. From then on, one will devote himself to work and pursue a further promotion of high skills to perfection in a virtuous circle. Give full play to this internal force to promote the refinement of craftsman spirit.

Although this research is about the higher vocational college students' cultivation of craftsman spirit, it abandons the current practice that many studies focus on students in schools. It is 
difficult for the students with little working experience to understand the influencing factors of enterprise. Therefore, this study limits the research objects to the graduates who have carried out graduation practice and are about to graduate and those who have graduated with three years' working experience. It is found that the cultivation of craftsman spirit is a systematic project. Among them, enterprises attach the greatest importance to craftsman spirit and have the greatest influence on training. The influence of schools, society and individuals is equal, Therefore, the cultivation of craftsman spirit of students in higher vocational colleges is not only the responsibility of higher vocational colleges, but also requires schools, enterprises, society, families and individuals to play a joint role with the enterprises' immersion experience learning education, the schools' infiltration solidification and the internalization-driven inheritance of society-family-individuals to promote the cultivation of craftsman spirit.

\section{Acknowledgements}

This project was sponsored by China Scholarship Council \&Humanities and Social Sciences Planning Fund Project of the Ministry of Education of the People's Republic of China (\#18YJA880002).

\section{References}

[1] Akiyama Lihui. Trans. Chen Xiaoli. Artisan Spirit [M]. Beijing: CITIC Publishing House, 2015, 5.

[2] Lewis, Harry. Trans. Hou Dingkai. Excellence without Soul: How Harvard Forgets Its Educational Purpose [M]. Shanghai: East China Normal University Press, 2012, 30.

[3] Lu Baoli, Yang Fei, Wang Yanan. Reconstruction and Inheritance: Research on Chronology Engineering of Chinese Artisan Spirit [J]. China Vocational and Technical Education, 2016, (34): 124-134.

[4] Hu Bing, Li Xiaolu. On the New Mission of Ideological and Political Education in higher vocational colleges [J], Exploration of Higher Education, 2015, (5): 85-89.

[5] Li Defu, Liao Yi. Evolution and Enlightenment of "Artisan Spirit" in China, Germany and Japan [J]. China University Science and Technology, 2016, (07): 46-48.

[6] Cheng Hong, Tian Hongmiao. Does the lack of craftsman spirit lead to low product quality? [J]. Macro Quality Research, 2016, (4): 1-10.
[7] Manova K. Multi-product Firms and Product Quality [J]. Nber Working Papers, 2012, 18 (1): 19-39.

[8] Hasenkamp H. Innovation through Craftsmanship [J]. Management and Marketing, 2013, 18 (5): 46-65.

[9] Foege, A. The Tinkerers: The Amateurs, DIYers, and Inventors [M]. New York: Basic Books, 2013, (2): 200-228.

[10] Xiao Qunzhong, Liu Yongchun. Artisan spirit and its contemporary value $[J]$. Hunan Social Sciences, 2015, (06): $6-10$.

[11] Tang Yan, Ji Aiqin. Cultivation of craftsman spirit in higher vocational education [J]. Journal of Nantong University (Social Science Edition), 2017, 33 (01): 142-148.

[12] Alec Fauci. Artisan Spirit: An Important Force to Create Great Legends [M], Hangzhou: Zhejiang People's Publishing House, July 2014.

[13] Li Jin. Research on the Contemporary Value and Cultivation Path of Artisan Spirit [J]. China Vocational and Technical Education, 2016, (27): 27-30.

[14] Yang Hongquan, Su Wei, Research on the Cultivation of Contemporary "Artisan Spirit" Based on Modern Apprenticeship [J]. On Vocational Education Tan, 2016, (16): 27-32.

[15] Ma Yinqiu, Ma Canjing. The Times Calls for the Return and Remodeling of Craftsman Spirit-Thinking on Enterprise Management Culture in View of Japan's "Family Yuan System Structure" [J]. Social Science Forum, 2017, (4): 238-245.

[16] Polach. Understanding the Experience of College Graduates During the First Year of Employment [J]. Human Resource Development Quarterly, 2004, 15 (1): 66.

[17] Cheng Haitao. The lack of craftsman spirit and the mission of higher vocational colleges $[\mathrm{J}]$. Vocational Education Forum, 2016, (22): 79-82.

[18] Liu Qing. The realistic dilemma and rational thinking of cultivating "artisan spirit" in higher vocational colleges [J]. Exploration of Higher Vocational Education, 2017, 16, (01): 5-10.

[19] Kuang Ying. The era meaning and cultivation path of "artisan spirit" under the background of intelligence [J]. Research on Educational Development, 2018, (1): 43.

[20] Tan $\mathrm{Lu}$. Research on the cultivation of craftsman spirit in local engineering colleges facing "Made in China 2015" [J]. Heilongjiang Higher Education Research, 2018, (5): 150. 